Brit. Heart f., 1967, 29, 829.

\title{
Supravalvar Stenosis of the Pulmonary Artery
}

\author{
F. G. SCHLESINGER AND G. T. MEESTER
}

From the Department of Cardiology, University Hospital, Utrecht, the Netherlands

Narrowing of the pulmonary artery at some site distal of the valves is considered a congenital anomaly which is probably related to maternal rubella (Arvidsson et al., 1961; Emmanouilides, Linde, and Crittenden, 1964; Gyllenswärd et al., 1957; Heiner and Nadas, 1958; Rowe, 1963).

Since the embryological genesis of the condition has not yet been elucidated, anatomical classification at present rests entirely on shape and location of the narrowed segment.

Three main types are distinguished (Hudson, 1965; Nieveen et al., 1961; Smith, 1958; Søndergaard, 1954; Wagenvoort, Heath, and Edwards, 1964):

Type I: Single or multiple stenoses of the pulmonary arteries; either in the main pulmonary trunk, its primary branches, or more peripherally.

Type II: Stenosis of the bifurcation of the pulmonary trunk; "coarctation of the pulmonary artery".

Type III: Membranous stenosis immediately above the pulmonary valve; "supravalvar stenotic shelf" (Fig. 1).

The diagnostic problems of supravalvar pulmonary stenosis and its importance in surgery are related to its frequent association with other congenital cardiovascular anomalies.

The following associated lesions have hitherto been described:

(1) Pulmonary valvar stenosis (Baum et al., 1964; Coles and Walker, 1956; Emmanouilides et al., 1964; Löhr, Loogen, and Vieten, 1961; Luan et al., 1960; Rowe, 1963; Shumacker and Lurie, 1953; Søndergaard, 1954; Vermillion, Leight, and Davis, 1958; Williams, Lange, and Hecht, 1957).

Received February 9, 1967.

2
(2) Infundibular pulmonary stenosis (Baum et al., 1964; Löhr et al., 1961; Williams et al., 1957).

(3) Fallot's tetralogy (Baum et al., 1964; Löhr et al., 1961; Luan et al., 1960; Søndergaard, 1954).

(4) Ventricular septal defect (Eldridge, Selzer, and Hultgren, 1957; Emmanouilides et al., 1964; Löhr et al., 1961; Luan et al., 1960; Rowe, 1963; Vermillion et al., 1958; Williams et al., 1957).

(5) Atrial septal defect (Arvidsson, Karnell, and Möller, 1955; Eldridge et al., 1957; Löhr et al., 1961; Søndergaard, 1954; Williams et al., 1957).

(6) Patent ductus arteriosus (Emmanouilides et al., 1964; D’Silva, Dillon, and Gasul, 1957; Luan et al., 1960).

(7) Agenesis of the left pulmonary artery (Baxter, Booth, and Sirak, 1961; Schmitz and Thurn, 1958).

(8) Total anomalous pulmonary venous return (Eldridge et al., 1957).

From our own material, to be discussed in this paper, we add:

(9) Aortic valvar stenosis ( 2 cases).

(10) Aortic insufficiency ( 1 case).

(11) Coarctation of the aorta (1 case).

Paradoxically, the so-called "associated lesions" assume paramount importance in any discussion of the practical aspects of supravalvar pulmonary stenosis. In the first place, the clinical symptomatology and the results of catheterization and angiography may be distorted beyond recognition by the hæmodynamic consequences of the associated lesions. Correct diagnosis may thereby become extremely difficult. Secondly, in the surgical management of the associated lesions the presence of supravalvar pulmonary stenosis introduces a num829 

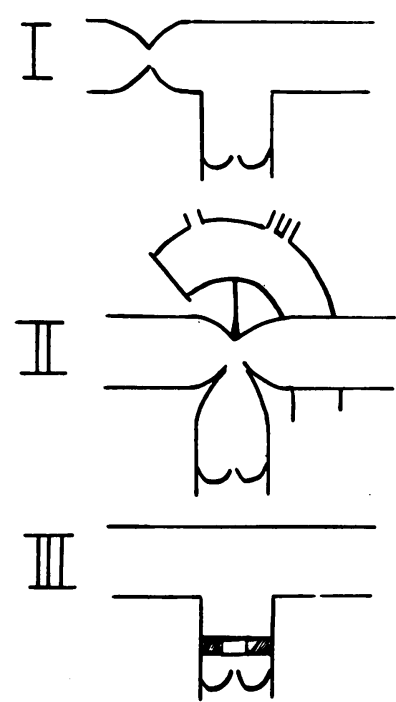

Fig. 1.-The three main types of supravalvar pulmonary stenosis (see text).

nition imperative. The operative procedure should then be planned accordingly.

In view of these problems, we felt that the information gained with present diagnostic methods in 14 patients might be useful.

\section{SUBJECTS AND METHOdS}

Fourteen patients ( 8 men, 6 women), whose ages

TABLE I

ANATOMICAL TYPE OF SUPRAVALVAR PULMONARY STENOSIS IN 14 PATIENTS

\begin{tabular}{l|c}
\hline \multicolumn{1}{c|}{ Anatomical type of stenosis } & No. \\
\hline Stenosis of one primary branch & 5 \\
Stenosis of both primary branches & 6 \\
Stenosis of right primary branch and atresia of left & 1 \\
Stenosis of both primary branches and common trunk & 1 \\
Membranous stenosis & 1 \\
\hline Total & 14 \\
\hline
\end{tabular}

TABLE II

OTHER CARDIOVASCULAR ANOMALIES IN 9 OF 14 PATIENTS WITH SUPRAVALVAR PULMONARY STENOSIS

\begin{tabular}{l|c}
\hline \multicolumn{1}{c|}{ Anomalies } & No. \\
\hline Ventricular septal defect & 1 \\
Atrial septal defect (ostium secundum type) & 2 \\
Pulmonary valvar stenosis & 1 \\
Atresia of left main branch & 1 \\
Aortic valvar stenosis & 2 \\
Coarctation of the aorta & 1 \\
Aortic insufficiency & 1 \\
\hline \multicolumn{1}{c|}{ Total } & 9 \\
\hline
\end{tabular}

ranged from 6 to 37 years, underwent complete clinical examination, including a normal 12-lead electrocardiogram, vectorcardiography following the Frank system, and phonocardiography with an Atlas 6-channel recorder.

Catheterization studies were performed with the Telco-equipment, using the micromanometer-catheter for intracardiac pressure recording and phonography. In all patients right heart catheterization and retrograde left heart catheterization were applied.

Pulsed cine-angiocardiography was performed by means of a Philips 9-inch image amplifier and a $35 \mathrm{~mm}$. Arriflex camera; the original $35 \mathrm{~mm}$. negative film was copied onto $16 \mathrm{~mm}$. positive film with the aid of a reduction-printer. The film frequency was set at $\mathbf{5 0}$ frames a second (Chaillet, 1965).

\section{RESULTS}

The various types of supravalvar pulmonary stenosis encountered in our 14 patients are summarized in Table I. In 9 of these patients associated cardiovascular anomalies were diagnosed (Table II).

By means of left heart catheterization and angiography from the left ventricle we were able to diagnose a number of coexisting conditions (aortic valvar stenosis, aortic insufficiency, coarctation of the aorta) which, to our knowledge, have not yet been described with supravalvar pulmonary stenosis.

Auscultation and Phonocardiography. The auscultatory findings in supravalvar pulmonary stenosis are not very different from those commonly encountered in valvar pulmonary stenosis: that is, a systolic murmur at the basis of the heart to the right or left of the sternum, often accompanied by a thrill (Fig. 2).

There are, however, a number of clinical and phonocardiographic signs, which make one suspect supravalvar pulmonary stenosis. The pulmonary component of the second sound ("second pulmonary sound") which is weak or even inaudible in other types of pulmonary stenosis is quite loud and may be audible along the whole left sternal edge and at the apex (Fig. 3). This sign depends on the pressure just above the pulmonary valve in relation to right ventricular pressure. Since, in most types of distal pulmonary artery stenosis, the pressure in the pulmonary trunk just beyond the valve is normal or even raised, a normal or loud pulmonary closing sound is produced. Sometimes a continuous systolic-diastolic murmur is encountered, which has occasionally led to confusion with patent ductus arteriosus (Arvidsson et al., 1955; Eldridge et al., 1957; Shafter and Bliss, 1959; Grosse-Brockhoff, 1961). The murmur may be found in any location on the thorax, depending upon the anatomical type of the distal pulmonary stenosis. 


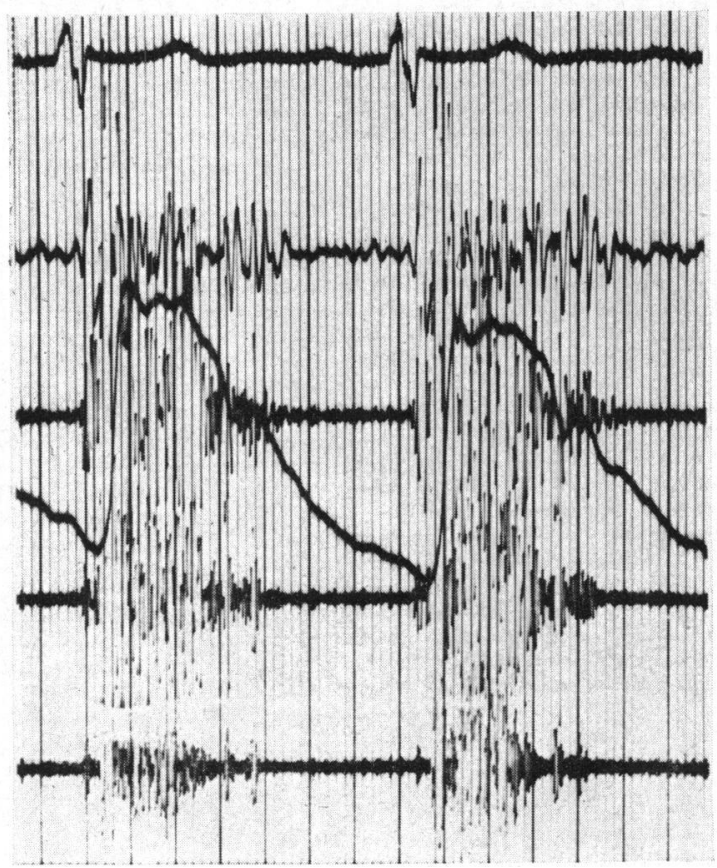

FIG. 2.-External phonocardiogram of a patient with the membranous type of supravalvular stenosis, complicated by an atrial septal defect (see text). Site: second intercostal space, at right sternal edge. Channels: electrocardiogram and carotid tracing as reference curves. Sound recordings with Maasz-Weber filters at nominal frequencies of $35,70,140$, and 250 c.p.s.
TABLE III

SPLITTING OF SECOND SOUND IN 12 PATIENTS WITH SUPRAVALVAR PULMONARY STENOSIS

\begin{tabular}{l|c|l}
\hline & No. & $\begin{array}{c}\text { Right ventricular pressures } \\
\text { (mm. Hg) }\end{array}$ \\
\hline $\begin{array}{l}\text { Narrow and inconstant } \\
\text { splitting (0-50 msec) }\end{array}$ & 6 & $\begin{array}{c}18 /-1 ; 20 / 41 ; 24 / 2 / 5 ; \\
29 /-6 / 0 ; 40 / 1 / 5 ; \\
50 /-1 / 4\end{array}$ \\
$\begin{array}{c}\text { Constant splitting due to } \\
\text { RBBB (60 msec.) }\end{array}$ & 2 & $24 / 0 / 6 ; 28 / 0 / 2$ \\
$\begin{array}{c}\text { Wide splitting (60-80 msec.) } \\
\text { Single 2nd sound }\end{array}$ & 3 & $45 / 1 / 3 ; 52 / 4 ; 64 / 0$ \\
\hline Total & 1 & $120 / 0$ \\
\hline
\end{tabular}

Wide splitting (60-80 m.sec. or more) of the second sound is generally present in valvar pulmonary stenosis; the presence or absence of this feature in supravalvar stenosis depends on the hæmodynamic conditions (Table III).

Electrocardiography and Vectorcardiography. The electrocardiogram and vectorcardiogram reflect the hæmodynamic situation. Therefore, with increasing right ventricular pressures, gradual transition from normal up to right ventricular hypertrophy was found (Table IV).

The vectorcardiogram was used to distinguish more accurately between right bundle-branch block, right ventricular preponderance, and right ventricular hypertrophy (Boutkan, 1965; Grishman, 1965) (Fig. 4). The electrocardiogram is

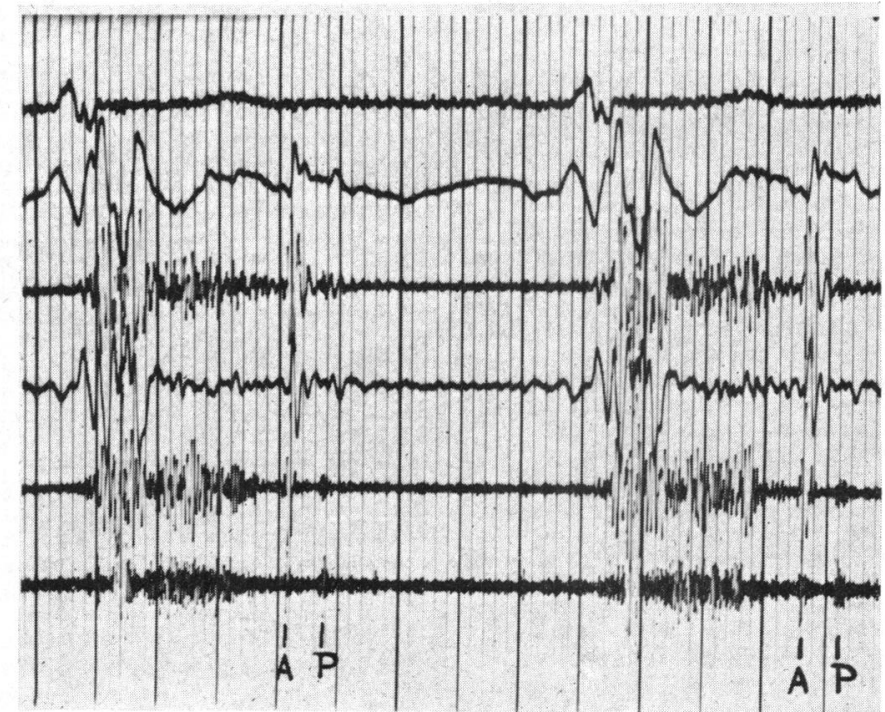

FIG. 3.-External phonocardiogram of same patient as Fig. 2. Site: at the apex. Channels: electrocardiogram as reference curve, sound recordings without filter, with the "earlike" filter (nominal frequency: 140 c.p.s.) and Maasz-Weber filters at 35,140 , and 250 c.p.s. $A=$ Aortic closure. $\mathbf{P}=$ Pulmonary closure, which is well marked (see text). 


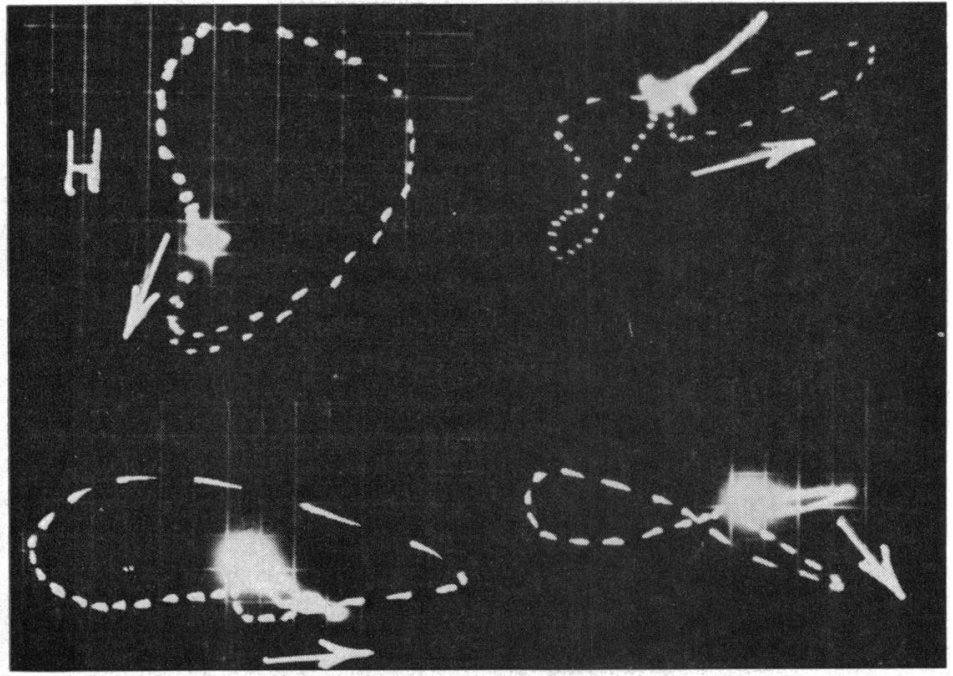

FIG. 4.-Vectorcardiogram (Frank system): shape of the horizontal loop. Left upper: normal QRS loop which runs anticlockwise. Left lower: QRS loop in right ventricular preponderance, which runs anticlockwise but has a large terminal loop to the right. Right upper: QRS loop in right bundle-branch block; the greater part of the QRS loop runs fairly normally but the final section shows a delayed and sluggish deflection to the right. Right lower: QRS loop in right ventricular hypertrophy; it is deflected back towards the right in its first part and then runs clockwise.

greatly influenced by associated left ventricular anomalies, and one patient, in whom we also diagnosed valvar aortic stenosis, showed clear-cut left ventricular hypertrophy.

Cardiac Catheterization. The characteristic finding on the withdrawal curves is a rise in the pulmonary artery pressure on passage of the supravalvar stenosis (Fig. 5). If the catheter is withdrawn into the right ventricle, the contour of the pressure curve will change in two steps.

At first sight the recognition of supravalvar stenosis on a catheter/pressure record may not seem too difficult, but it may escape detection even where it has been specifically looked for (Agustsson $e t$ al., 1962). Stenosis of the membranous type, where the

\section{TABLE IV}

ELECTROCARDIOGRAM AND VECTORCARDIOGRAM IN 10 PATIENTS WITH SUPRAVALVAR PULMONARY STENOSIS

\begin{tabular}{|c|c|c|}
\hline $\begin{array}{l}\text { Electrocardiogram and } \\
\text { vectorcardiogram }\end{array}$ & No. & $\begin{array}{c}\text { Right ventricular pressures } \\
(\mathrm{mm} . \mathrm{Hg})\end{array}$ \\
\hline $\begin{array}{l}\text { Normal } \\
\text { Right bundle-branch block } \\
\text { Right ventricular prepon- } \\
\text { derance } \\
\text { Right ventricular hyper- } \\
\text { trophy }\end{array}$ & $\begin{array}{l}3 \\
2 \\
4 \\
1\end{array}$ & $\begin{array}{l}18 /-1 ; 24 / 2 / 5 ; 29 /-6 / 0 \\
24 / 0 / 6 ; 28 / 0 / 2 \\
40 / 1 / 5 ; 45 / 1 / 3 ; 52 / 4 ; 64 / 0 \\
120 / 0\end{array}$ \\
\hline Total & 10 & \\
\hline
\end{tabular}

membrane is often situated only $0.5-1.5 \mathrm{~cm}$. distal of the valve, may easily be missed unless the catheter is withdrawn extremely slowly. In addition, in the presence of an important pulmonary valve stenosis, flow may be so reduced that a concomitant peripheral stenosis does not yield a detectable pressure drop (Williams et al., 1957). The presence of pulmonary valvar stenosis with previously undetected supravalvar stenosis has important surgical implications (Thrower, Abelmann, and Harken, 1960).

From our record (Fig. 5) it will be evident that the intracardiac phonogram shows a loud systolic murmur peripheral from the stenosis. As soon as the catheter has been withdrawn past the stenotic site, the murmur disappears. The intracardiac phonogram, in combination with oximetry and selective angiocardiography, may be most helpful in excluding some sources of error. A pressuregradient may be simulated by withdrawing the catheter from the "wedge" position (Williams et al., 1957). Pressure changes within the pulmonary artery system may be found when the tip of the catheter passes the pulmonary orifice of a patent ductus arteriosus (Levinson et al., 1951). Small pressure gradients between the primary branches and the main pulmonary artery may be found as a "functional gradient" in conditions with a large pulmonary blood flow due to a left-to-right shunt (Zimmerman, 1966).

The hæmodynamic data found in our series of 14 patients may be summarized as follows. 


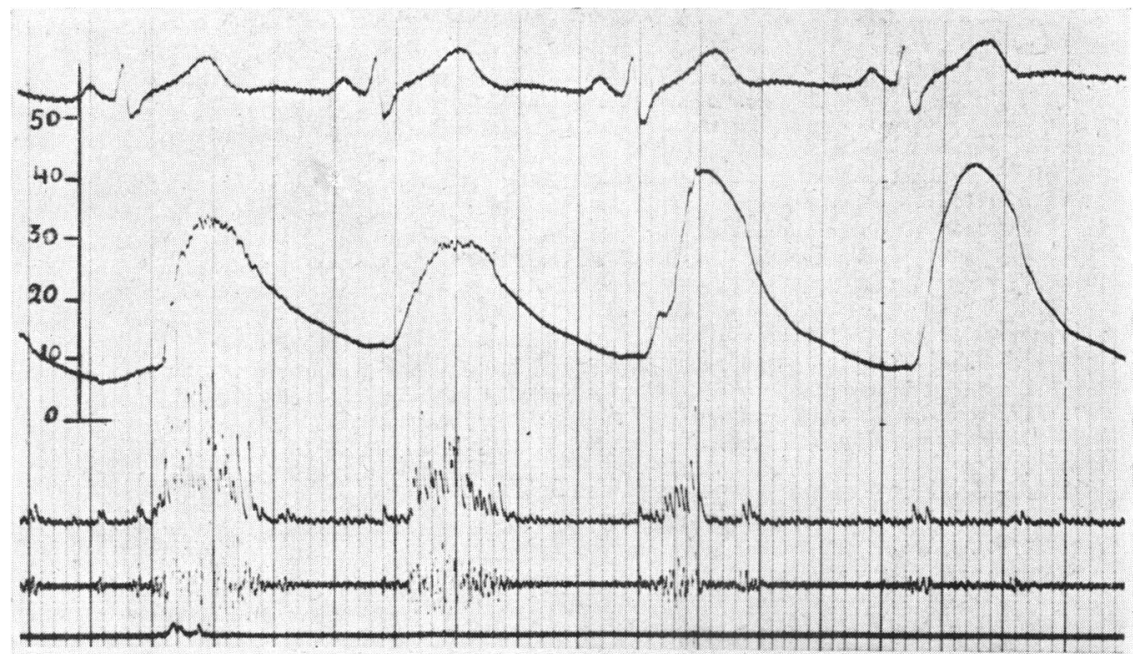

FIG. 5.-Withdrawal curve from peripheral to main pulmonary artery, passing the stenosis. The 5 channels represent: (1) electrocardiogram, (2) pressure, (3) envelope of total intracardiac sound, (4) total intracardiac sound, (5) envelope of intracardiac sound above 1000 c.p.s.

Stenosis of one primary branch was found in 5 patients. In 4 of them, the systolic pressure gradient over the stenosis was quite small (range: from 4 to $12 \mathrm{~mm} . \mathrm{Hg}$ ) and the pressure in the right ventricle was not increased. In one patient, a systolic gradient of $32 \mathrm{~mm} . \mathrm{Hg}$ was found between distal pulmonary artery and main pulmonary trunk; this patient had a raised right ventricular pressure (Table V). Stenosis of both primary branches and/ or the main pulmonary trunk was found in 9 patients. In 7 of them (including one patient with the membranous type of stenosis) the right ventricular pressure was raised.

In 2 patients, with uncomplicated bilateral branch stenosis and extremely small gradients across the stenosis, the right ventricular pressure had remained normal (Table VI). It appears, therefore, that the hæmodynamic consequences are

TABLE V

HEMODYNAMIC STUDIES IN 5 PATIENTS WITH STENOSIS OF ONE PRIMARY BRANCH

\begin{tabular}{|c|c|c|c|c|c|}
\hline $\begin{array}{l}\text { Case } \\
\text { No. }\end{array}$ & $\begin{array}{c}\text { Stenosed } \\
\text { branch }\end{array}$ & $\begin{array}{l}\text { Other car- } \\
\text { diovascular } \\
\text { anomalies }\end{array}$ & \begin{tabular}{|} 
Pulmonary \\
artery: \\
distal \\
pressure \\
(mm. Hg)
\end{tabular} & $\begin{array}{c}\text { Pulmonary } \\
\text { artery: } \\
\text { trunk } \\
\text { pressure } \\
\text { (mm. Hg) }\end{array}$ & $\begin{array}{l}\text { Right } \\
\text { ventricular } \\
\text { pressure } \\
(\mathrm{mm} . \mathrm{Hg})\end{array}$ \\
\hline $\begin{array}{l}1 \\
2 \\
3\end{array}$ & $\begin{array}{l}\text { Right } \\
\text { Left } \\
\text { Left }\end{array}$ & 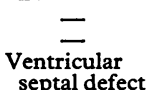 & $\begin{array}{l}19 / 8 \\
18 / 6 \\
12 / 6\end{array}$ & $\begin{array}{l}23 / 9 \\
50 / 4 \\
24 / 8\end{array}$ & $\begin{array}{l}24 / 0 / 6 \\
52 / 4 \\
29 /-6 / 0\end{array}$ \\
\hline $\begin{array}{l}4 \\
5\end{array}$ & $\begin{array}{l}\text { Right } \\
\text { Left }\end{array}$ & Coarctation & $\begin{array}{l}18 / 12 \\
11 / 4\end{array}$ & $\begin{array}{l}22 / 12 \\
15 / 4\end{array}$ & $\begin{array}{l}24 / 2 / 5 \\
20 /-1 /+2\end{array}$ \\
\hline
\end{tabular}

TABLE VI

HEMODYNAMIC STUDIES IN 9 PATIENTS WITH STENOSIS OF THE PULMONARY TRUNK AND/OR TWO PRIMARY BRANCHES

\begin{tabular}{|c|c|c|c|c|c|c|}
\hline \multirow{2}{*}{$\begin{array}{l}\text { Case } \\
\text { No. }\end{array}$} & \multirow[t]{2}{*}{ Site of stenosis } & \multirow{2}{*}{$\begin{array}{l}\text { Other cardiovascular } \\
\text { anomalies }\end{array}$} & \multicolumn{2}{|c|}{$\begin{array}{l}\text { Pulmonary artery: } \\
\text { distal (mm. } \mathbf{H g})\end{array}$} & \multirow{2}{*}{$\begin{array}{c}\text { Pulmonary artery: } \\
\text { trunk }(\mathrm{mm} . \mathbf{H g})\end{array}$} & \multirow{2}{*}{$\begin{array}{l}\text { Right ventricle } \\
(\mathrm{mm} . \mathrm{Hg})\end{array}$} \\
\hline & & & Right & Left & & \\
\hline 1 & Right and left & Secundum type atrial & $9 / 4$ & & $94 / 7$ & $97 /-5 / 4$ \\
\hline $\begin{array}{l}2 \\
3 \\
4 \\
5 \\
6\end{array}$ & $\begin{array}{l}\text { Right and left } \\
\text { Right and left } \\
\text { Right and left } \\
\text { Right and left } \\
\text { Right and left and } \\
\text { bifurcation }\end{array}$ & $\begin{array}{l}\text { Aortic stenosis } \\
\text { Aortic insufficiency } \\
\text { Aortic stenosis }\end{array}$ & $\begin{array}{l}14 / 7 \\
27 / 12 \\
56 / 16 \\
18 / 12 \\
-\end{array}$ & $\begin{array}{l}17 / 7 \\
24 / 11 \\
50 / 12 \\
18 / 8 \\
-\star\end{array}$ & $\begin{array}{l}18 / 6 \\
28 / 10 \\
60 / 18 \\
50 / 10 \\
\end{array}$ & $\begin{array}{l}18 /-1 \\
28 / 0 / 2 \\
64 / 0 \\
50 /-1 / 4 \\
120 / 0\end{array}$ \\
\hline $\begin{array}{l}7 \\
8\end{array}$ & $\begin{array}{l}\text { Right and left } \\
\text { Membranous }\end{array}$ & $\begin{array}{l}\text { Valvar pulmonary stenosis } \\
\text { Secundum type atrial }\end{array}$ & $\begin{array}{l}21 / 4 \\
27 / 16\end{array}$ & $\begin{array}{l}19 / 6 \\
27 / 16\end{array}$ & $\begin{array}{l}33 / 5 \\
45 / 12\end{array}$ & $\begin{array}{l}58 /-4 / 0 \\
45 / 1 / 3\end{array}$ \\
\hline 9 & Right and left & Atresia of left branch & $30 / 10$ & - & $40 / 9$ & $40 / 1 / 5$ \\
\hline
\end{tabular}

* Catheter could not be passed into the pulmonary trunk. 


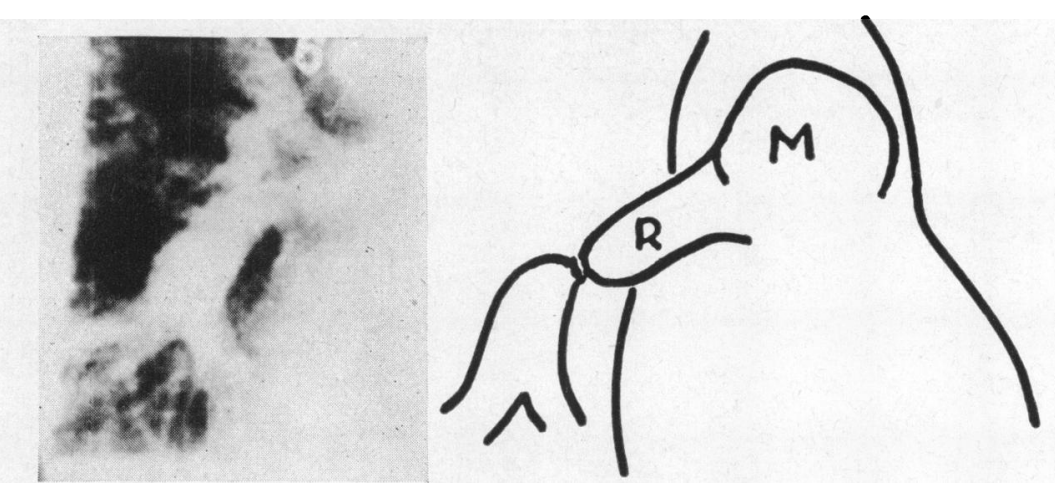

FIG. 6.-Angiocardiogram showing stenosis of right main branch; frontal view projection. $M=$ main pulmonary artery; $R=$ right branch.
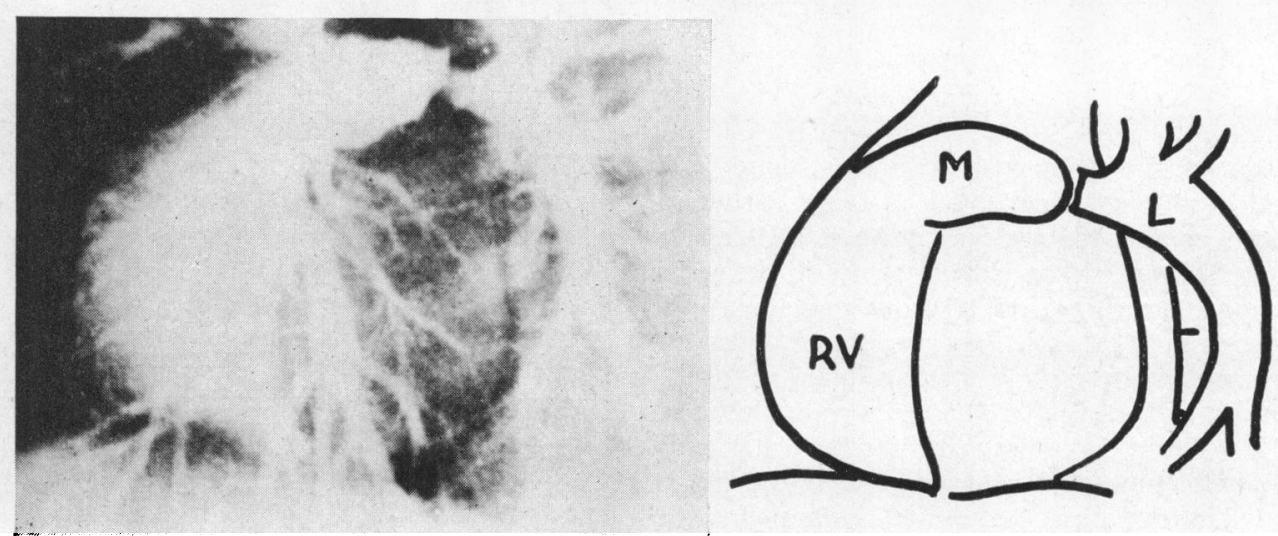

FIG. 7.-Angiocardiogram showing stenosis of left main branch; left anterior oblique projection. $M=$ main pulmonary artery; $L=$ left branch; $R V=$ right ventricle.
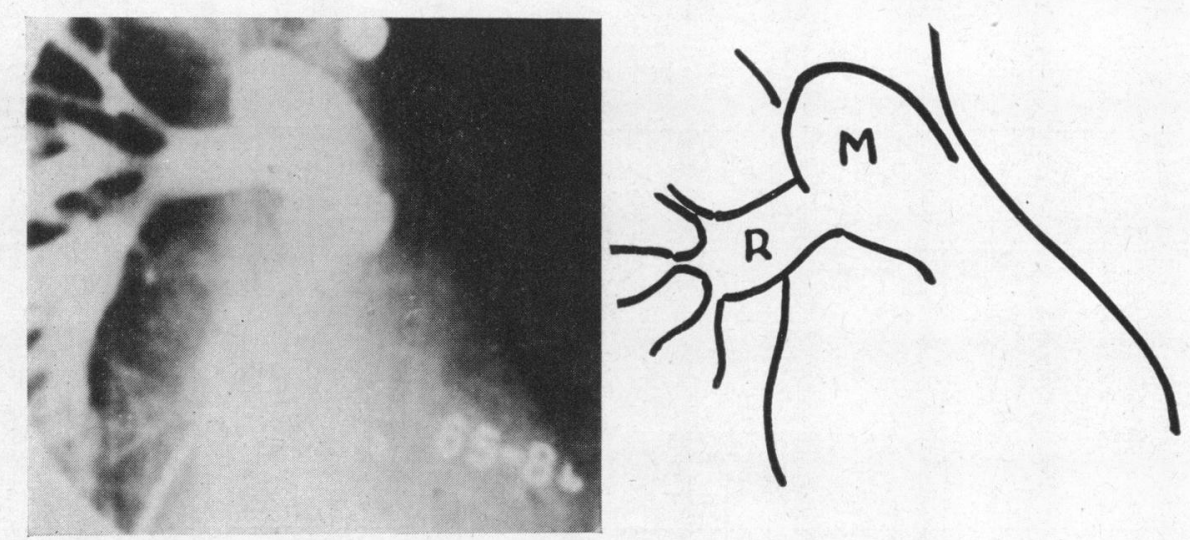

FIG. 8.-Angiocardiogram showing atresia of left branch and multiple peripheral stenoses of the right pulmonary artery, with post-stenotic dilatation: frontal projection. $M=$ main pulmonary artery; $R=$ right branch. 


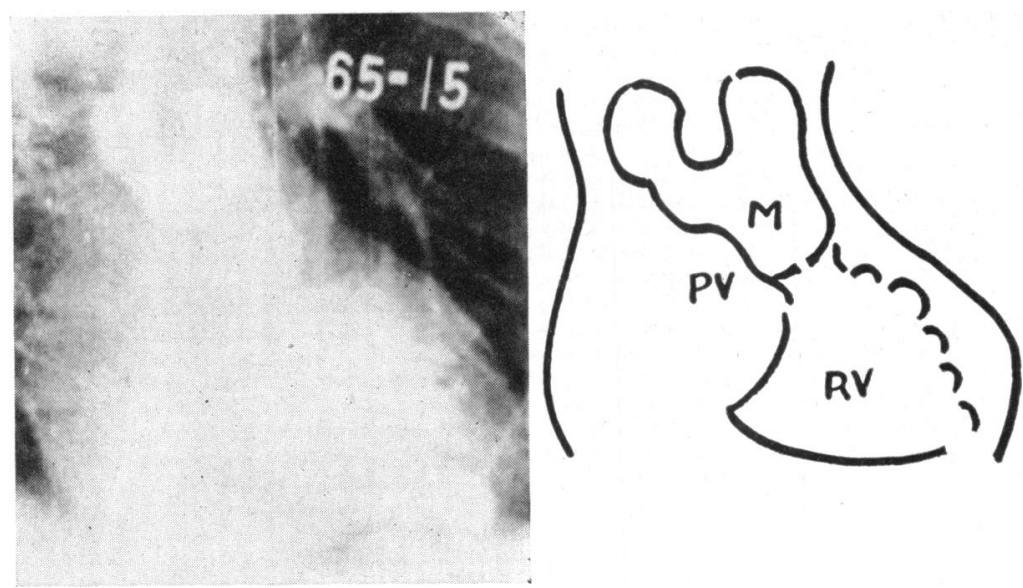

FIG. 9.-Angiocardiogram showing serious deformation of the main trunk, the bifurcation, and both main branches; frontal projection. $M=$ main pulmonary artery; $P V=$ level of pulmonary valve; $R V=$ right ventricle.

determined by the anatomical type of the lesion and the pressure-gradient over the stenotic part.

Selective Angiocardiography. If the pressure records obtained on catheterization suggest stenosis of a pulmonary branch or at the bifurcation, then the contrast medium should be injected into the main pulmonary trunk (Fig. 6, 7, 8). If the pressure recordings suggest the membranous type of stenosis or stenosis of the main trunk, then the injection should be made into the right ventricle (Fig. 9).

The diagnosis when the angiographic appearances are typical is fairly easy, but quite often it is impossible to discern the stenotic site. In the branch type of stenosis difficulties related to projection may frustrate adequate demonstration. In membranous stenosis, situated close to the pulmonary valves, the angiographic picture may be indistinguishable from valvar pulmonary stenosis.

\section{Discussion}

Though the first description of supravalvar pulmonary stenosis dates back as far as 1938 (Oppenheimer, 1938), the clinical importance of this anomaly was not fully realized until the advent of modern cardiac surgery (Søndergaard, 1954).

The surgical implications are important. In the immediate post-operative phase after open intracardiac operation for atrial septal defect, total anomalous pulmonary venous connexion, or atrial septal defect, increased resistance to right ventricular outflow constitutes a serious hazard to life. Unfortunately, as we have shown, the congenital anomalies are frequently associated with supra- valvar pulmonary stenosis, and in their surgical management pre-operative recognition and eventually correction of the pulmonary artery stenosis may decide the outcome of the operation (Kirklin and Theye, 1963; Rehder, Kirklin, and Theye, 1962; Theye and Kirklin, 1963).

Narrowed segments of the main pulmonary branches may complicate anastomotic procedures involving a systemic artery and a pulmonary artery (Baum et al., 1964).

Since the pre-operative diagnosis of supravalvar pulmonary stenosis may be impossible in the presence of pulmonary valve stenosis because the flow is too small to yield an appreciable pressure gradient, and since unrecognized and uncorrected pulmonary artery stenosis jeopardizes the outcome of pulmonary valve surgery, operations for pulmonary valve stenosis should as a rule be performed with cardiopulmonary bypass (Thrower et al., 1960).

The supravalvar pulmonary stenoses are important in so far as they may occasionally give rise to a continuous murmur which has to be differentiated from patent ductus arteriosus.

If the murmur is only of the systolic type, then it may appear that supravalvar pulmonary stenosis alone accounts for an otherwise unexplained systolic murmur.

Lastly, the interesting observations of Falkenbach et al. (1959) are relevant. They studied the relationship of unilateral pulmonary artery stenosis to pulmonary hypertension. Their work in dogs suggests that while removal of an entire pulmonary main branch does not raise the pressure in the lesser circulation, a rise in pressure is observed after partial occlusion of a main branch. These authors 
contemplate the possibility of liberation of a hormonal substance from the ischæmic lung as the basis of this phenomenon.

At present, however, unilateral branch stenosis in man will generally not require surgical correction and the membranous type and bifurcation type stenosis will have to be treated according to the hæmodynamic situation.

\section{SUMMARY}

The clinical and hæmodynamic data in 14 patients with different types of supravalvar pulmonary stenosis are analysed. In 9 patients the condition was associated with other cardiovascular anomalies. In 4 patients left-heart catheterization revealed the presence of aortic valvar stenosis in 2, coarctation of the aorta in 1, and aortic insufficiency in 1 patient.

These associated conditions make the clinical symptomatology very complicated and a correct diagnosis can only be made by combining pressure curves, oximetry, intracardiac phonography, and selective angiocardiography. The practical importance of pre-operative diagnosis of supravalvar pulmonary stenosis in the surgical management of the so-called "associated lesions" is discussed.

The authors are indebted to A. W. Philippi for his help with the vectorcardiographic analysis.

\section{REFERENCES}

Agustsson, M. H., Arcilla, R. A., Gasul, B. M., Bicoff, J. P., Nassif, S. I., and Lendrum, B. L. (1962). The diagnosis of bilateral stenosis of the primary pulmonary artery branches based on characteristic pulmonary trunk pressure curves. Circulation, 26, 421.

Arvidsson, H., Carlsson, E., Hartmann, A., Jr., Tsifutis, A., and Crawford, C. (1961). Supravalvar stenoses of the pulmonary arteries. Acta radiol. (Stockh.), 56, 466.

—, Karnell, J., and Möller, T. (1955). Multiple stenosis of the pulmonary arteries associated with pulmonary hypertension, diagnosed by selective angiocardiography. Acta radiol. (Stockh.), 44, 209.

Baum, D., Khoury, G. H., Ongley, P. A., Swan, H. J. C., and Kincaid, O. W. (1964). Congenital stenosis of the pulmonary artery branches. Circulation, 29, 680.

Baxter, C. F., Booth, R. W., and Sirak, H. D. (1961). Surgical correction of congenital stenosis of the right pulmonary artery accompanied by agenesis of the left pulmonary artery. $\mathcal{F}$. thorac. cardiovasc. Surg., 41, 796.

Boutkan, J. (1965). Vectorcardiography. Physical Bases and Clinical Practice, pp. 100-107. Centrex Publishing Company, Eindhoven.

Chaillet, J. L. (1965). Cineradiography of cardiac valves in man. Thesis, Utrecht. (Printed by J. D. van der Horst, Utrecht.)

Coles, J. E., and Walker, W. J. (1956). Coarctation of the pulmonary artery. Amer. Heart f., 52, 469.

D'Silva, J. L., Dillon, R. F., and Gasul, B. M. (1957). Syndrome of stenosis of the right pulmonary artery. (Abstr.) Circulation, 16, 911.
Eldridge, F., Selzer, A., and Hultgren, H. (1957). Stenosis of a branch of the pulmonary artery: an additional cause of continuous murmurs over the chest. Circulation, 15, 865.

Emmanouilides, G. C., Linde, L. M., and Crittenden, I. H. (1964). Pulmonary artery stenosis associated with ductus arteriosus following maternal rubella. Circulation, 29, 514.

Falkenbach, K. H., Zheutlin, N., Dowdy, A. H., and O'Loughlin, B. J. (1959). Pulmonary hypertension due to pulmonary arterial coarctation. Radiology, 73, 575.

Grosse-Brockhoff, F. (1961). Periphere pulmonal stenose. Cardiologia (Basel), 38, 142.

Grishman, A. (1965). Spatial vectorcardiography. In $E x-$ amination of the Cardiac Patient, ed. A. A. Luisada, p. 4. McGraw-Hill, New York.

Gyllenswärd, A., Lodin, H., Lundberg, A., and Möller, T. (1957). Congenital multiple peripheral stenoses of the pulmonary artery. Pediatrics, 19, 399.

Heiner, D. C., and Nadas, A. S. (1958). Patent ductus arteriosus in association with pulmonic stenosis: a report of six cases with additional noncardiac congenital anomalies. Circulation, 17, 232.

Hudson, R. E. B. (1965). Cardiovascular Pathology. E. Arnold, London.

Kirklin, J. W., and Theye, R. A. (1963). Cardiac performance after open intracardiac surgery. Circulation, 28, 1061.

Levinson, D. C., Cosby, R. C., Griffith, G. C., Meehan, J. P., Zinn, W. J., and Dimitroff, S. P. (1951). A diagnostic pulmonary artery pulse pressure contour in patent ductus arteriosus found during cardiac catheterization. Amer. F. med. Sci., 222, 46.

Löhr, H., Loogen, F., and Vieten, H. (1961). Die periphere Pulmonalstenose. Fortschr. Röntgenstr., 94, 285.

Luan, L. L., D'Silva, J. L., Gasul, B. M., and Dillon, R. F. (1960). Stenosis of the right main pulmonary artery. Circulation, 21, 1116.

Nieveen, J., van der Slikke, L. B., Que Giok Sien, and de Vries, H. (1961). Coarctation of the pulmonary artery. Cardiologia (Basel), 38, 239.

Oppenheimer, E. H. (1938). Partial atresia of the main branches of the pulmonary artery occurring in infancy and accompanied by calcification of the pulmonary artery and aorta. Bull. Fohns Hopk. Hosp., 63, 261.

Rehder, K., Kirklin, J. W., and Theye, R. A. (1962). Physiologic studies following surgical correction of atrial septal defect and similar lesions. Circulation, 26, 1302.

Rowe, R. D. (1963). Maternal rubella and pulmonary artery stenoses; report of eleven cases. Pediatrics, 32, 180.

Schmitz, H., and Thurn, P. (1958). Zur Asymmetrie der Lungenarterien. Fortschr. Röntgenstr., 88, 133.

Shafter, H. A., and Bliss, H. A. (1959). Pulmonary artery stenosis. Amer. F. Med., 26, 517.

Shumacker, H. B., Jr., and Lurie, P. R. (1953). Pulmonary valvulotomy. Description of a new operative approach with comments about diagnostic characteristics of pulmonic valvular stenosis. F. thorac. Surg., 25, 173.

Smith, W. G. (1958). Pulmonary hypertension and a continuous murmur due to multiple peripheral stenoses of the pulmonary arteries. Thorax, 13, 194.

Søndergaard, T. (1954). Coarctation of the pulmonary artery. Danish med. Bull., 1, 46. (Cited by Arvidsson, Karnell, and Möller, 1955.)

Theye, R. A., and Kirklin, J. W. (1963). Physiologic studies following surgical correction of ventricular septal defect. Circulation, 27, 530. 
Thrower, W. B., Abelmann, W. H., and Harken, D. E. (1960). Surgical correction of coarctation of the main pulmonary artery. Circulation, 21, 672.

Vermillion, M. B., Leight, L., and Davis, L. A. (1958). Pulmonary artery stenosis. Circulation, 17, 55.

Wagenvoort, C. A., Heath, D., and Edwards, J. E. (1964).
The Pathology of the Pulmonary Vasculature. C. C. Thomas, Springfield, Illinois.

Williams, C. B., Lange, R. L., and Hecht, H. H. (1957). Postvalvular stenosis of the pulmonary artery. Circulation, 16, 195.

Zimmerman, H. A. (1966). Intra-vascular Catheterization, 2nd ed. C. C. Thomas, Springfield, Illinois. 